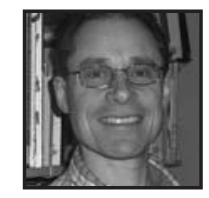

\title{
(Re) conceiving Student Engagement: What the Students Say They Want. Putting Young People at the Centre of the Conversation
}

\author{
David Zyngier, Monash University
}

\section{ABSTRACT}

The challenge of student engagement has been recognised as a serious issue, especially in the middle years of schooling in Australian education. This qualitative study seeks to understand the experiences of one group of students beginning their high school years. Students are often left out of the discourse on student engagement. Traditionally they are objectified and omitted from the dialogue because often they are viewed as products of formal education systems. By giving voice to students, I compare and contrast the various and contested understandings of authentic or generative aspects of student engagement and what these might mean for classroom practice. I suggest that pedagogical practices that connect to students' lives are too often ignored but necessary elements of teacher pedagogy for all students, particularly, those from disadvantaged and minority backgrounds. I identify and examine three contesting epistemological constructs of student engagement in order to answer three interrelated questions: (i) What are the most worthwile conceptions of engagement? (ii) What are the purposes of engagement? (iii) Who benefits (and who is excluded) from these purposes? I conclude that not all forms of student engagement are equal.

\section{Introduction}

ngagement is difficult to define operationally, but we know it when we see it, and we know it when it is missing (Newmann, 1986, p 242). 
Pedagogical practice always implies a struggle over assigned meaning, a struggle over discourse as the expression of both form and content, as struggle over the interpretation of experience and a struggle over "self". But it is this very struggle that forms the basis of a pedagogy that liberates knowledge and practice. It is a struggle that makes possible new knowledge that expands individual experience and, hence, redefines our identities and the real possibilities we see in the daily conditions of our lives. The struggle is itself a condition basic to the realization of a process of pedagogy: it is struggle that can never be won-or pedagogy stops. It is the struggle through which new knowledge, identities, and possibilities are introduced that may lead to the alteration simultaneously of circumstance and selves (Simon, 1992, p. 69).

This paper is a part of research that analyses, through the voices of teachers and students, changing pedagogical practices in one school. Informed by Haberman's Pedagogy of Poverty (1991) and Shor's Empowering Pedagogies (1987, 1992, 1996), I suggest that resistance is not the antithesis but rather, the contradictory act of engagement, while accommodation is a self-protective negative agency in response to unequal power relations. Three contesting constructions of student engagement previously identified (Zygier, 2004) are examined through the (often but not necessarily) contesting and resisting voices of teachers and students. In conclusion, I ask how might we (re) conceive student engagement in order to achieve the twin goals of social justice and academic achievement (Butler-Kisber \& Portelli, 2003) through an empowering and resistant pedagogy.

\section{Methodology}

As part of an action research project involving the pedagogical development and change of a team of teachers in a disadvantaged, working class state high school, I analysed multiple forms of data that included narratives from semi-structured interviews with teachers and students, as well as, teacher self-surveys of their pedagogy. Beachside Secondary College is a public (government) school of some 800 students from Year 7 to Year 12 located in the southeast bay-side region of Melbourne. The school began as a state technical (vocational) school in 1968 largely serving the population of the surrounding low-rise public housing community. In 1986 , it was compulsorily and reluctantly amalgamated with the neighbouring academic high school during a period of forced school closures and amalgamations. 
I interviewed the teachers individually. Students, in their first year of high school, were interviewed in small focus groups, one group for each teacher's class. The students were asked to reflect on their teachers' attempts to modify their pedagogies in an endeavour to engage them. This empirical, qualitative study seeks to understand the experiences of one group of students beginning their high school years.

Students are often left out of the discourse on student engagement since, as Murphy (2001) claims, they are frequently looked upon as the products of formal education systems. By giving voice to students, I compare and contrast the various and, sometimes contesting, understandings of what authentic or generative student engagement might mean for both school and classroom practice. I argue that a pedagogical practice that connects to the real life of all students, including those from disadvantaged and minority backgrounds, is an often-ignored, but necessary, element of teacher pedagogy. The student voices are privileged here. They are given the opportunity, together with their teachers, to enter into the discourse about the contrasting and sometimes conflicting views of what student engagement looks like in their classrooms. This paper seeks to understand not only how student engagement is defined by teachers and students, but how it is enacted in the classroom. That is, whether it replicates the status quo or strives for equity and social justice.

The challenge of student engagement has been recognised as a serious issue, especially in the middle years of schooling in both Australian and Canadian education. Vibert \& Shields (2003) define engagement as:

... a continuum, ranging from relatively rational and technical approaches to those that are more constructivist, to those reflecting a critical democratic worldview...not only is this a descriptive continuum, but .... move from the rational, through the interpretivist, to a more critical understanding, ...a more socially grounded construction of "engagement." (Vibert \& Shields, 2003, p. 237)

At the beginning of the 21 st Century, there has been a significant interest in and concern with student retention, participation and achievement rates in postcompulsory schooling within Western education systems. By way of response, governments and schools have developed many programs that aim to improve engagement and, ultimately, educational outcomes for all students, particularly those identified as being "at-risk of disengagement." 
Curriculum that is relevant to the needs and interests of students is important (Zyngier, 2003). But it also matters what teachers do with respect to student learning. The research of Newmann (1996), Newmann, Bryk \& Nagaoka (2001), and Lingard, Ladwig, Mills, Bahr, Chant, Warry et al. (2001) suggests that certain pedagogies can have positive effects on student engagement in learning, even for those students who are at risk of academic failure. There is growing evidence that teacher change that modifies the quality of the pedagogical experiences for their students may result in quantitative improvements in both academic achievement and recognitive social justice (Gale \& Densmore, 2000). Recognitive social justice is concerned not just with the redistribution of goods and services, but also a rethinking of social arrangements that are currently accepted as just, giving status to action that is currently thought to be counterproductive and decentering concerns thought to be pivotal (Gale, 2000, p. 253). This assertion does not suggest that teachers are the difference, or alternatively, the problem in relation to student achievement (Gale, 2006). Hattie (2003) claims that teachers contribute about $30 \%$ to student achievement and stresses that "it is what teachers know, do, and care about which is very powerful in this learning equation" (Hattie, 2003, p. 2). Hattie emphatically adds:

Schools barely make a difference to achievement. The discussion on the attributes of schools - the finances, the school size, the class size, the buildings are important as they must be there in some form for a school to exist, but that is about it (Hattie, 2003, p. 2).

While Instrumentalist and socio-constructivist research suggests-influenced in turn by retributive and redistributive understandings of social justice-that student outcomes are most influenced by students' home background and individual characteristics, Rowe (2004a) concludes that these have less than $10 \%$ of the variance:

The magnitude of these effects pales into insignificance compared with class/ teacher effects. That is, the quality of teaching and learning provision are by far the most salient influences on students' cognitive, affective, and behavioural outcomes of schooling, regardless of ... student background. (Rowe, 2004, p. 4 [emphasis in original]). 


\section{Contesting Discourses of Engagement}

The phrase "engagement in school" or "student engagement" is often cited as an essential component of programmatic interventions for at-risk students. However, there have been very few attempts to define engagement, other than behaviourally, or to study it as part of the learning process. Researchers acknowledge that definitions of engagement encompass a wide variety of constructs that "can help explain how children behave, feel and think in school" (Fredricks, Blumenfeld, Friedel \& Paris, 2003, p. 6). The definitions are commonly a mix of (i) behavioural aspects, (ii) affective or emotional feelings, and, (iii) cognitive engagement that includes motivation, effort, and strategy use.

Much of the research essentialises engagement, portraying it, and the academic success that accompanies it, as a function of the individual, ignoring the contribution of gender and socio-cultural, ethnic, and economic status (class) factors. Finn's (1989) participation/identification model has been readily adopted in Australia (Fullarton, 2002) and is characterised by associating lack of engagement with poor academic performance. According to this view, as schools become more effective, students are more engaged and academic performance is thus improved (Fredricks, Blumenfeld, \& Paris, 2004). These views portray student engagement as something that teachers can organise for them and do to them (Luse, 2002, emphasis added). This concept of student engagement does not take into account that some students may be playing by the rules of the game as described by Haberman (1991).

Students who reject (for any reason) the values of the school are generally labelled as alienated or disengaged. Schlechty (2002) recognises that even students who withdraw or retreat are making conscious decisions about their schooling.

Where engagement is narrowly defined as "willingness to become involved in teacher-initiated tasks" and is separated from the students' socioeconomic and cultural contexts, engagement is, by and large, viewed as the responsibility of the teacher. But if the student is disengaged then the problem is with the student. I would argue that this correlation between participation and achievement is a misinterpretation made by the proponents of Finn's participation/identification model (Fullarton, 2002). The reification of this definition of student engagement results in the identification and measurement of only those conditions that seem to encourage or impede it. 


\section{Social Justice and Engagement: Three Contesting Perspectives}

Previously I (Zyngier, 2004) described three dominant perspectives accounting for engagement as (i) instrumentalist or rational technical, (ii) social constructivist or individualist, and, (iii) critical transformative. Each of these discourses is situated within the contesting teacher and student voices from Beachside Secondary.

\section{Instrumentalist or Rational Technical}

An instrumentalist or rational technical understanding of student engagement is fundamentally objectivist. It focuses on counting the number of students who are involved in either curricular (such as being on task or completing assigned work) or in extracurricular activities. Minimal or no attempt is made to "go beneath the surface": that is, to understand the meaning that students make of the activity or their motivation to participate.

Teachers at Beachside are committed and well intentioned, exhibiting initiative and effort to involve students in numerous activities. Built on teacher initiation, that is, doing to or for, rather than doing with:

These activities are common to most schools and are illustrative of teachers trying, in various ways to develop both pedagogical and social activities in which students may be both involved and interested (Vibert \& Shields, 2003, p. 227).

A dominant deficit view prevails among many of the teachers reflecting the attitude that students and parents are either competent or capable because of their background. For example, Dom puts all the "blame" on the students or their background because they:

...become disengaged, or are not interested in doing it, of course, because it is too difficult. Other things [that cause lack of engagement] don't involve anything in this room or in this classroom ... because of factors that don't involve the teacher. It could be external issues. ... I have students that come to class and I don't think that much would engage them because they have some injury or some incident outside the school that distracts them. ... I don't think a classroom teacher can help much. I think that it goes back to diet and habits at home, how they prepare themselves ... before they come to school, ... the 
home, ... the TV watching that goes on, the family situation. ... you can almost see from the student, ... what the family is going to be like as well.

In my research, students entering a new school after seven years of primary education shared many of the common (usually baseless) fears about going to the "big school." All the students interviewed were convinced that the level of academic work was not going to be just harder and greater, but also challenging and exciting. Most of the students had expected that the level and volume of academic work at Beachside would be dramatically increased from what they had previously experienced. A student commented that:

I thought it would be a lot harder and a lot more work ... and more challenging for me. ...I thought I was going to get more homework ... and go home and have to stay up late and finish all our homework.

Yet the students interviewed were insistent that teachers were giving them work that was far too easy for them. A number of students expressed disappointment that the work was not as varied or as difficult as they had thought it would be such that:

I just want some hard work ... Year 7 isn't as hard as I thought it would be. It is usually the same as primary school, the same work, it is not that hard really. Some of the fast workers like me get our work done. The teachers have nothing for us to do and we have to sit there and do nothing. ... I found grade 6 harder ... like it was more challenging because I knew I didn't want to get kept down, in primary school it was harder for me. ...I have to say year 7 isn't harder (from various students).

Despite identification that their own engagement was important to their outcomes, many students accepted that some of the work, even if it did not offer an instant interest to them at this stage, would be of benefit to them in the future. hooks (2003) suggests that "many students stop the practice of learning because they feel learning is no longer relevant to their lives... They have learned ... that book learning offered ... has no relevance in the world outside ..." (hooks, 2003, p. 42). Even though they are only just beginning secondary school, students were already considering the long term benefits of academic success. The danger here is that gratification delayed may become gratification denied, leading to, at best, passive or ritualistic engagement or, at worst, retreatist, rebellious, or resistant forms of engagement (Schlechty, 2002). Various students commented that: 
Not every work is fun, like some things can be boring but you have got to do it.... You need to get used to the homework because you are going to get a lot of it in year 12 and 11. I get bored with the maths, but I still do it - I know that I need a good education to get into university and to pass year 12. I don't like it but I still do it. When you do harder work you understand more. I just try my hardest at it because I don't know yet what I want to do when I am older, but I want to go to Uni[versity] and I know you need good marks to be able to get into Uni, so I try my hardest at everything.

Some of the teachers located the problem in the background of the student as exemplified in Sally's words...

Their skills are so weak, they are frighteningly weak, that these children can't read ... we have really got to work on their basic skills. How can they go off and research independently when they can't read?

Their parents too are reduced to being passive recipients of school-based programs rather than being empowered to be active partners in their children's educational development (Smith, Butler-Kisber, LaRocque, Portelli, Shields, Sturge Sparkes, \& Vibert, 2001, p. 132). Their style of pedagogy is typical of what Giroux (1994) criticised as "education for slackers" and Lingard (2006) as "pedagogies of indifference."

Shor (1987) concludes that "through this vast vocational matrix, the great majority of the working class pass, getting a narrow skills-on-the-job training which is identified as education" (p.25). Clearly these teachers separate the curriculum from the every-day concerns of the students, where academic studies are separated from self-concept and behaviour (Vibert, Portelli J, Shields, \& Laroque, 2002). They are not prepared-as Giroux suggests is essential — "to fashion alternative analyses in order to understand what is happening to youth" (Giroux, 1994, p. 210).

\section{Social Constructivist or Individualist Engagement}

Social constructivist or individualist engagement is a more student-centred pedagogy. It envisages engagement as implicit in active learning where students experience self-motivation, reflective and shared goal setting, and choice. This notion of engagement certainly produces more dignified and interesting classrooms. However, it does not necessarily raise substantive (and critical) student inquiry that questions the acceptance of official knowledge (Apple, 1993) for all students, not just 
those of the middle class. Some Beachside teachers share this view of engagement as demonstrated in Theo's thoughts:

I think the more we can pour our energies into helping individual students [the better but] I think the other thing too we are trying to teach en masse some will pick it up, some won't. The ones that pick it up ... are the independent learners that have the skills to go about learning and I guess our job is to bring more of those students that aren't able to, to get them to the level.

Shor (1992) points out that situating learning in the students' subjectivity and relating the subject area to student experience must be the "starting point, [followed by] the social context of the larger culture, and the academic context" (Shor, 1992, p. 145). Teachers can be well meaning, but often unwittingly perpetuate stereotypes about the capabilities of, in this case, working class and recently arrived migrant students who they feel inevitably lower school standards. Such teachers believe they have to lower standards for these "backward students" (hooks, 2003, p. 17).

Some Beachside teachers equate engagement with compliance to and participation in pre-determined adult rules and adult-led activities. This form of engagement produces underachievement by marginalised students who actively "resent and resist an alien culture imposed on them" (Shor, 1992, p. 202). The words of the teacher identified as Sally voices Shor's concerns. She concludes that for her students, the "culture of schooling has failed to train them in the dominant discourse and practices" (Shor, 1992, p. 203) and says:

There is a disregard for education, there is lack of respect for themselves, for their peers, for authority. I was hoping that we would have that opportunity to mould them, mould the children ... because ... they don't value education.... I think it is really important that our students know how to fit into society.

Vibert and Shields (2003), echoing Sefa Dei (2003), claim that the student alone cannot interrupt officially sanctioned discourses since "the right choices are powerfully inculcated in institutional habits, routines ... what in this context might student choice mean?" (p. 7) in a system of schooling where domination is perpetuated. Shor (1987) comments that:

Powerlessness results from feeling overwhelmed by an oppressive yet incomprehensible system. The contradictory presence and elusive aspects 
of social control lead to confusion about what freedom is or what the means are to be free, happy and whole. (p. 56-57)

This reality is exemplified when Sally introduced the animated film Shrek with:

Now you have all got to shut up and listen because you are going to do a project on this. You know ... the person who said it would know that that wouldn't be the right way to present it, obviously, but sometimes when the kids are screaming ... you just say things without thinking.

In such a situation, shared decision-making is an illusion for students when they are unable to question and overcome their own marginalisation. Haberman (1991) indicates that in such situations low self-esteem can cause even brilliant students to self-sabotage. As Dom indicates:

I can be as compassionate as possible, working within a group of 25 students, and then when other students see that compassion, not so much compassion, favouritism I guess you can call it, in their eyes, then they jack up.

Student-centred or social constructivist engagement defaults to a conservative position and "may become simply a more friendly method of encouraging ontask behaviour" (Vibert and Shields, 2003, p. 8). So while a student remarks...

No one really likes Miss because she like yells at us for nothing and gives us detention for nothing and it just gets annoying.

His teacher explains that:

I think it is really important that we do explain and help them to see why they are doing it. The notion 'let the child decide what they want to learn' I just don't think they know what they want or they certainly don't know what they need to know.

Shor (1992) explains that even when students "trust the good intentions" of teachers, they have "already learned in traditional classes that a good student keeps quiet and agrees with the teacher" (p. 93). Too often in student-centred teaching, teachers make uncritical or make-believe connections between classroom learning 
and the world outside of the school. In this situation, as Theo explains, a teachers design activities that:

Initially I thought ... would be engaging because I thought ... it would be interesting or engaging enough to maybe do a bit more in depth unit on it. But because they had done it before, they seemed to say ... it's boring.

Contrary to the "commonsense view" (McDonald, 2002) of constructivist pedagogy, Goodman (1992) and Shor (1996) suggest that this approach often promotes a false student-centredness. Teachers perceive this work to be engaging because they "simulate real-world environments ... so that students can carry out authentic tasks as real workers would ..." (Day, 2002, p. 23). Sing and Luke (1996) caution that pedagogy based on "unproblematic notions of individualism and liberalism which attempt to recognise and celebrate difference per se" (p. xiii) can actually conceal pedagogical practices that are the cause of inequality of opportunity and outcomes for the disadvantaged in schools. Etta, the Student Coordinator at Beachside, understood this connection.

I found it really difficult that teachers were teaching this stuff but they weren't making any connections and perspectives of how that reflects in the real world and why they needed to do that.

Shor (1987) criticises this individualist pedagogy because it fails to problematise the examination of a real context drawn from student experience without criticizing his/her daily life. Many of Etta's colleagues assign engagement to the individual student leading to an essentialisation and reification of engagement. Students (teachers and the community) are, therefore, engaged when the school is an engaging place, but as Sally explains, because...

The students we get here are weak, just incredibly weak ... we have to look at various ways in which we can approach our subjects to engage the kids and to develop their skills in the area.

\section{Critical-Transformative Engagement}

Thus, student-centred pedagogy sees engagement through student exploration and discovery of individual interests and experiences. Critically transformative or generative pedagogy, on the other hand, (Zyngier, 2003) defines student engagement as a rethinking these experiences and interests in communal and social terms 
for the purpose of creating a more just and democratic community, not solely for the advancement of the individual. All students should be able to see themselves represented in a curriculum that challenges hierarchical and oppressive relations existing between different social groups. Pedagogical reciprocity acknowledges that the lives of children and their communities are a curriculum of life (Smith et al., 1998, 2001), not just connected to student experience, but also actively and consciously critiquing the experience. This "situated teaching from everyday life" (Shor, 1992, p. 44) rejects the superficial fixation on student interest that Shor (1992) describes as a "static entrapment in what students already know and say. What students bring to class is where the learning begins. It starts there and goes places" (p. 44). One teacher, Nelly, realised that:

I ... found a whole heap of things [that] they knew ... that they didn't think that they knew. Like they had these realisations of this knowledge and kids are like "I know that." ... they had this knowledge but they had never realised they had it....[I]t wasn't packaged, like normally a kid will come in and go "in science I know this" and this wasn't information that was packaged in their head, it was just in there, ... I think that is where you notice how much other things outside influence and that is the information that they don't have packaged up.

A colleague, Shelley, realizes that the teacher is responsible for reversing passiveness and provoking involvement, and understands the cognitive and affective levels of the class into which serious study is situated (Shor, 1992, p. 54). She suggests that what is important is for students to:

...feel safe and supported in the classroom, that relationship stuff is really important and talking an interest in them, not just yelling at them because they are late to the class.

Some students recognised that they were not as engaged in the secondary high school as they had been at the primary level. They identified a number of possible reasons for this.

She (the teacher) comes up and yells in your face and it is like you don't want to be there. ... Well everyone doesn't like her because she is grumpy and all that, but I think she is only grumpy because everyone is mean and doesn't listen to what she says. ... always yelling and ... cranky. Favouring other students and not having enough work prepared. ... She is always going off at kids for doing something wrong and we are not getting as much help as we want. 
They also suggested disruption caused by other students prevents engagement.

They [other students] don't really learn it because they are too busy shouting and getting kicked out of the room, so they don't really learn what they are supposed to, so the work is hard for them.

Sometimes the work is too easy and and repeats work already done.

Teachers have to explain it to us so that we actually know, like if they don't explain it to us properly, not like "here you go."

The students were quite clear that if they could see a purpose to learning, they would be more likely to do the work, even if it was something in which they were not particularly interested. Reflecting Haberman's (1991) critique that classroom practice is not necessarily determined and imposed by the teacher, students commented that:

It is just basically if you crack it you are better off out there because you can calm down. If the teachers get really frustrated ... they will make you come back inside. The teachers usually decide, but if you are in a bad mood and you walk out, they will decide whether they want to come and get you, or whether you can calm down and then they will come and get you.

Haberman (1991) raises the problematic stance that disadvantaged students are most likely to reject out-of-hand (at least initially) new approaches that include intellectually challenging work in favour of repetitive, non-challenging and educationally debilitating work. A student noted this type of situation:

There are people that try and ruin class time to [just] get out of it.

Sally, his teacher, responded with words reminiscent of transmissive or instrumentalist discourse:

I know that if you write notes on the board and say "nobody goes until they are done" they are little angels and they will just sit there and copy it out but we all know that while we are doing that, we are doing it to buy ourselves a bit of respite.... [W] know that they are not learning anything doing that, so I don't want to teach like that. But the minute you just relax, actually ... lighten up a little bit ... mayhem breaks out, so you go back to your little tight 
world again. They are just a nasty group, they are horrible to each other, there is incredible bullying and misery, they are just not nice. ... [this class] couldn't give a damn. No they couldn't care less.... I really do not know what to do to engage those students. I would say with all their teachers we have all tried a myriad of approaches but we are not getting anywhere, I don't know what the answer is.

Another student added this about Sally.

Everyone doesn't like her because she is grumpy and all that, but I think she is only grumpy because everyone is mean and doesn't listen to what she says and she goes and gets the co-ordinator and she comes and talks to us, or goes off at us or something.

This sort of demonisation where teachers see students always as their enemy makes the teacher part of the problem rather than part of the solution. Sally may already hate her job and her students, feeling that the classroom situation has become pathological (Schlechty, 2002) and that disciplinary issues are making it impossible to teach. Not only does she feel doomed, says hooks (2003), but she is:

...condemned to stay in the prison of work she no longer [seems] to want to do ... the students she teaches are also condemned, compelled to remain in a setting where the only hope of learning is the gaining of information from formulaic lesson plans (p. 15).

If it is correct that teachers often operate in a classroom with an unwritten contract (Haberman, 1991) of "don't stress me and we won't disrupt your class," then change cannot be found solely in modifying the curriculum. Lynn, who the students rate as "a good teacher," reflects that:

First of all, there are particular teachers that need to admit that their classes aren't operating the way that they want to. I have found that to be a little bit disheartening sometimes that you can quite clearly see that something wrong is happening in the classroom, something is going on that shouldn't be but the teachers response is "oh no, it is ok, it's fine" that has been frustrating.

While Sally is obviously disillusioned with teaching, Lynn takes a different standpoint, one that while revealing a "strange and threatening landscape ... moves beyond illusion, so that [she] sees reality in the round-since what we are able to see 
depends entirely on where we stand" (Palmer as cited in hooks, 2003, p. 20-21). Haberman (1991) suggests that marginalized students may still resist such efforts even when the teacher intends to create opportunities for improved educational outcomes (McFadden \& Munns, 2002, p. 361). Recognizing this, Nelly commented that:

They resist it because they don't understand it, like the way that I grew up or the way I see the world now or the way I live isn't the way that they see the world, isn't the influences that they have.

Kanpol's (1997a) research into similar "cynical eighth graders" describes the coping strategies of students as a counter-hegemonic agenda, that is, as forms of institutional, political resistance noted by both teachers and students at Beachside.

The students that would not normally play up do, there is a lot of movement around the classroom. They tend to push the boundaries knowing that there is a different teacher in the classroom.

It is just some people, they crack it so much in the class, they will walk out, ... it doesn't happen all the time but some people, they just think they are having a bad day. They crack it with the teacher and they go into a bad mood because they are getting frustrated and they slam the door.

Counter-hegemonic resistance is mainly concerned with breaking rules, use of oppositional language and developing survival mechanisms that challenge authority. Institutional resistance is the result of subordinated groups forming "community on the basis of shared negative beliefs and understandings about oppression ... even as [students] identify ways the dominating culture keeps them down" (hooks, 2003, p. 73). They reinforce that power by seeing themselves only as victims perpetuating their own oppression as students who have lost "sight not only of their strength to resist but of the possibility that they can intervene and change the perspective of power" (hooks, 2003, p. 73). As one student surmised:

For a lot of them it would be, because they don't really learn it because they are too busy shouting and getting kicked out of the room, so they don't really learn what they are supposed to.

Lynn (the teacher) offered this perspective.

There is one particular student that is probably the smartest kid in the class, but he fails to hand in work on time, he does not complete homework as well. I think students know that they are breaking the rules and understand the 
implications as to what will happen but do not care. I think a difficult class is one that does not want be there and does not want to learn.

Another student added:

It is very noisy because none of us like the teacher and we just all crack it and we just do whatever we want and don't listen to the teacher.

"Confirmation bias" (hooks, 2003) sees that some teachers identify certain students as being less capable than others. These students begin to perform in ways that will satisfy the teacher's low expectations. The "pygmalion effect" (Rosenthal, \& Jacobson, 1968) is clearly evident at Beachside:

I have got quite a few students in my class that are not against throwing a chair if it means, and they have learnt this over years at school as well, they behave really poorly, you get sent out, you get suspended, they learn the system really quickly.... Some of these kids just don't want to be involved in what is going on.... They get in there and you are doing an activity that they don't like, or they have had a rough day and they just don't want to be involved. Some of the kids will do anything they can to get out of it, and they know how to get out of it.

Many of Beachside's teachers seem more comfortable with mediocrity because this serves as confirmation of what hooks (2003) refers to as a "deep seated belief in the [students'] inferiority" (p. 89). Dom concluded that:

If your students can't achieve what you expect them to achieve, just give them grade four work, they will succeed at that and say, well I have done my job. If our students have level four numeracy there is just no point forcing them to learn year 7 work if they have missed something.

Student resistance, therefore, can be distinguished from a more critical "substantive counter-hegemony of cultural political resistance" (Kanpol, 1997b, p. 5). In this form of resistance, students see themselves as represented in a curriculum that challenges hierarchical and oppressive relations existing between different social groups. Resistance can, however, turn to counter-hegemonic engagement through generative connectedness "found in the unsettled intersections of personal life and society" (Shor, 1992, p. 55). This type of engagement can be achieved through a focus on problems from student experience that is intellectually challenging, and a critical 
reflection that goes beyond opinion. Such engagement can be "problematic enough to inspire students to do intellectual work" (Shor, 1992, p. 5), even among "basic-skills" students. Nelly, perceiving that a resolution to this resistance is possible, comments that:

They have such skewed understanding of what is going on around them that you really need to base it on things that they understand and the things that begin are possibly the things that they feel comfortable with because jumping outside their comfort zone with some of our kids is not the best way to start something off.

Nelly takes student culture and connectedness seriously where other teachers may explicitly disagree with students and are prepared to argue student choices with them. Nelly understands that "empowering education is initiated and directed by a critical teacher but is democratically open to student intervention" (Shor, 1992, p. 85). She is of the opinion that:

If the students are engaged then they have an awareness of what is happening around them and an awareness of their options, and that is what I personally think engagement is all about.

In keeping with Haberman's (1991) view, students at Beachside were not interested in just having fun all the time but did want to be challenged as evident in the following comment.

\section{I think it is because we get bored, most of the time.}

Some of the teachers at Beachside, particularly Shelley and Nelly, recognised that they were being transformed as they taught students and as they learned from them. Such pedagogical reciprocity:

...disconfirms unilateral authority [and] by accepting student discipline, a power-sharing teacher then becomes democratically (not institutionally) authorised to make higher demands on the students because students have been authorised to make higher demands on the teacher (Shor, 1996, p. 125). 
Lack of student engagement was clear even to the students. Many felt that students "acted up" to get out of classes they found to be boring, and that some teachers were not effective in preventing these incidents within their classrooms. Low self-esteem tended to lead students to what hooks (2003) calls"self-sabotage" (p. 18). Failing to provide challenging work for capable students led them to becoming involved in disrupting others as suggested in these words.

They (worksheets) are just put on our tables and they just say "work" and make us work until the bell goes... I get bored after work, when I have finished all my work and I start getting bored and restless and throwing things around.... The teacher is too busy telling off the people that are shouting, they don't have enough time to come to you and help you.

Sometimes students seem to give up hope and do poorly in their work. They take on "... a mantle of victimhood. They fail. They dropout. Most of them have no guides to teach them how to find their way in the educational systems" (hooks 2003, p. 48). When schools are structured to maintain domination, they have within them subcultures of resistance where education "as the practice of freedom still happens" (hooks, 2003, p. 48). Students, in this study, recognised the need for greater teacher control. They observed that removing students from the class often resulted in more disruption to other classes.

And with other teachers they are like "Come in here" we are noisy and they give us a warning and they remind us again and it is like you are in for detention, the whole class, and with others they... teach us for a little while and then we get a bit noisy or people don't want to work and they just give up and they sit there looking.

Students who would otherwise stay on task became disruptive when teachers were not seen to be in control. Some students even mentioned that they were frightened to come to school because of the disruption. Students, however, were able to identify teachers and teaching pedagogies that effectively engaged them in their learning. They wanted teachers to learn from each other about what works.

Lynn teaches us literacy and English and she helps everyone and all that and when we do reading with her she puts us in different groups so that everyone is up to their own reading level. 
Teachers must change their pedagogical practices so that they deliver authentic pedagogy inequitable ways to all students regardless of gender, socioeconomic status, race or ethnicity (Newmann, 1996). It is incumbent on the teacher to become knowledgeable about the students she or he teaches and to structure curriculum around student experiences (Shor, 1992). Only a minority of Beachside teachers, however, expressed that transformative engagement was something for which teachers were responsible.

A good teacher does his or her homework first, student engagement starts off with... finding tasks that will keep the class really interested and student engagement is about self directed learning as well, and about clarity. If students know exactly what they have to do, why they have to do it and how they will be assessed, they are a lot more engaged then in photocopying a section out of a textbook, coming into class and saying "read this and answer these questions" because they can't link it to anything.

Etta acknowledged this differentiation clearly recognising that transformative engagement has the potential to disrupt the comfort zone of "confirmation bias"...

I look at the older teachers in our staffroom who are more senior ... they are more mature and ... from a [different] cultural background, I think that they should have had some sort of leadership role ... but they were as clueless as any of us.

\section{Increasing Engagement: Student Views}

All the students in this project could give examples of the kind of work and activities that made it easier to learn and that made them more likely to be attentive in class. These views are reflected in the following:

I would make it easier so that kids can get their say in what they do, because sometimes teachers don't listen... They made sure everyone knew how to do it. They won't go on with the work until they knew everyone knew how to do it.... To have 3 separate groups of intelligence levels for like how smart we are at maths or English.... To just jump ahead and learn as much as you can, get motivated.... The most enjoyable projects and all that we do would have to be 
the hands on stuff... [I want] a classroom where there are big tables and zero noise.

Students also expressed ideas that they felt teachers could use to make the lessons more rewarding. Interestingly, many of these were also suggested by some of the staff interviewed. As Etta indicated:

I am learning and I know that makes them learn too. They know that I am excited and they feel that I am involved so they keep wanting to learn because I keep wanting to learn. I don't say, "I am high and mighty, I am the teacher, you should find out." I tell them very honestly, "I don't really know, I have been learning just like you and I am still learning so you have to learn with me."

The few teachers who recognised the potential of transformative engagement to counter domination understood the value of risk. They saw that "the presence of conflict is not necessarily negative, but rather its meaning is determined by how we cope with that conflict" (hooks, 2003, p. 64), and like the students at Beachside, suggested that teachers need to "challenge themselves to teach beyond the classroom setting, to move into the world sharing their knowledge, and to learn a diversity of styles to convey information" (p.43).

A minority of Beachside teachers recognized that students should not only be valued, but they need to be given the opportunity to voice and discover their "own authentic and authoritative life in order to retrieve the learning agenda" (Giddens, 1994, p. 121). Such teachers understood that "the individual can act" and that his or her actions "have weight" (hooks, 2003). The more authority exercised by students, the more legitimacy is given to the authority of the teacher. In turn, students then have "less reason to sabotage the class and their own intellectual development" (Shor, 1996, pp.125-126). As the most transformative teacher at Beachside, Shelley commented that:

If the students are able to voice their opinions right from the start and get clear in their minds what their peers are saying about what they are doing, then students become more engaged. 


\section{Conclusion}

Important work is currently being undertaken in Australia (and elsewhere) on the kinds of pedagogies that improve outcomes for all students, (Lingard et al., 2001a; Lingard et al., 2001b; Newman et al., 2001) particularly those labelled as being at-risk of leaving school early, as disadvantaged, and/or from low socioeconomic backgrounds.

An engaging or "core" pedagogy should ensure that what teachers and students do involves connecting to and engaging with the students' cultural knowledge; owning or ensuring all students should be able to see themselves as represented in the work; responding to students' lived experiences and actively and consciously critiquing that experience; and empowering students with a belief that what they do will make a difference in their lives and giving them the opportunity to voice and discover their own authentic and authoritative life.

It is too simplistic to define engagement in terms of student deficiencies. Historically, the disengaged were those whose appearance, language, culture, values, communities and family structures were unlike to the dominant (white, middle-class) culture that schools were designed to serve and support (Hickson \& Tinzman, 1990; Alexander, 2000; hooks, 2003). The struggle over the definition of the term engagement is significant in itself for it reveals the ongoing ideological and epistemological divisions among educators, policy makers, and the general public. Research on student dis/engagement has shown that an exploration of the questions of class, power, history and, particularly, students' lived experiences and social reality reveal a complex set of factors that lead marginalised youth to leave school prematurely. It is, therefore, crucial that questions of power, equity, and engagement be addressed if we are to improve learning outcomes, not just for the most marginalised youth, but for all. This research suggests that the complexity of issues related to student engagement (and early school leaving), does not fit neatly into decontextualized accounts of youth experience, school interaction and socio-environmental factors-factors that create in the first instance student disempowerment and disengagement with school. Transformative student engagement is empowering. It develops a sense of entitlement, belonging, and identification where teachers, to quote hooks (1994), "create pedagogical practices that engage students providing them with ways of knowing that enhance their capacity to live fully and deeply" (p. 22). Otherwise, students are still "doing time, not doing education" (Sefa Dei, 2003, p. 251). 


\section{Notes}

1. Teacher names are pseudonyms to protect the anonymity of the participants and are quoted in Times font while student comments are in Times Italic font. All other quotations are in Arial font.

2. The analysis of the programmatic discourse in relation to understanding how the term engagement is used in education department and government policy documentation is beyond the scope of this paper.

3. All teacher names are pseudonyms. Teachers were individually interviewed in September, 2004, while all students are not named as their quotations come from group interviews in June, 2004.

\section{References}

Alexander, R. (2000). Culture and pedagogy: International comparisons in primary education. Oxford, UK: Blackwell.

Apple, M. (1993). Official knowledge: Democratic education in a conservative age. New York: Routledge.

Brown, J., \& Holdsworth, R. (2001). Building relationships, making education work: A report on the perspectives of young people. Canberra, Australia: The Commonwealth Department of Education, Training, and Youth Affairs, Australian Centre for Equity through Education and the Australian Youth Research Centre.

Butler-Kisber, L., \& Portelli, P. (2003). Editorial:The challenges of student engagement: Beyond mainstream conceptions and practices. McGill Journal of Education, 38 (2), 1-10.

Day, S. (2002) Real kids, real risks: Effective instruction of students at risk of failure. NASSP Bulletin, 86 (632), 19-32.

Finn, J. (1989). Withdrawing from school. Review of Educational Research, 59 (2), 117-142.

Fredricks, J., Blumenfeld, P., Friedel, J., \& Paris, A. (2003, March). School engagement: School Engagement. Paper presented at the Indicators of Positive development Conference, Washington DC.
Fredricks, J., Blumenfeld, P., \& Paris, A. (2004). School engagement: Potential of the concept, state of the evidence. Review of Educational Research, 74(1), 59-109.

Fullarton, S. (2002). Student engagement with school: Individual and school-level influences. Melbourne, Australia: Australian Council for Educational Research (ACER).

Gale, T. (2006). How did we ever arrive at the conclusion that teachers are the problem? A critical reading in the discourses of Australian schooling. In B. Doecke, M. Howie \& W. Sawyer (Eds.), 'Only connect ...': English teaching, schooling, and democracy. Kent Town: AATE \& Wakefield Press.

Gale, T., \& Densmore, K. (2000). Just Schooling: explorations in the cultural politics of teaching. London: Open University Press.

Giddens, A. (1994). Beyond left and right: The future of radical politics. Cambridge, UK: Polity.

Giroux, H.(1994). Education in the age of slackers. International Journal of Educational Reform, 3(2), 210-215.

Goodman, J. (1992). Elementary schooling for critical democracy. Albany, NY: State University of New York Press. 
Haberman, M. (1991). The pedagogy of poverty versus good teaching. Phi Delta Kappan, 73 (4), 290-294.

Hattie, J. (2003, October). Teachers make a difference: What is the research evidence? Paper presented at the conference of the Australian Council for Educational Research (ACER), Melbourne, Australia.

Hickson, J., \& Tinzman, M. (1990). Who are the "atrisk" students of the 1990s? Retrieved January 30, 2004, from http://ncrel.org /sdrs/areas/rpl_esys/equity.htm

hooks, b. (1994). Teaching to transgress: Education as the practice of freedom. New York: Routledge.

hooks, b. (2003). Teaching community: A pedagogy of hope. New York: Routledge.

Kanpol, B. (1997a). Issues and trends in critical pedagogy. Cresskill, NJ: Hampton.

Kanpol, B. (1997b). Reflective critical inquiry on critical inquiry: A critical ethnographic dilemma continued. The Qualitative Report, 3(4). [On-line serial] from http://www.nova.edu/ssss/QR/QR3-4/ kanpol.html

Lingard, B., Ladwig, J., Mills, M., Bahr, M., Chant, D., Warry, M., et al. (2001a). Queensland school reform longitudinal study: Final report (Vol.1). Brisbane, Australia: University of Queensland, School of Education.

Lingard, B., Ladwig, J., Mills, M., Bahr, M., Chant, D., Warry, M., et al. (2001b). Queensland school reform longitudinal study: Supplementary materials. Brisbane, Australia: University of Queensland, School of Education.

Lingard, B. (2006). Pedagogies of indifference: Research policy and practice. Paper presented at the conference of the Australian Association for Research in Education Adelaide University, Adelaide, Australia.

Luse, P. (2002). Speedwriting: A teaching strategy for active student engagement, The Reading Teacher, 56 (1), 20-22.

McDonald, C. (2002). Theories of the mind and the 'commonsense view'. Mind and Language, 17(5), 467-488.
McFadden, M., \& Munns, G. (2002). Student engagement and the social relations of pedagogy. British Journal of Sociology of Education, 23(3), 357-366.

Murphy, S. (2001).“No-one has ever grown taller as a result of being measured" revisited: More educational measurement lessons for Canadians. In J. P. Portelli \& R. P. Solomon (Eds.), The erosion of democracy in education (pp. 145-167). Calgary: Detselsig.

Newmann, F. M. (1986). Priorities for the future: Towards a common agenda. Social Education, 50(4), 240-250.

Newmann, F. (1996). Authentic achievement: Restructuring schools for intellectual quality. San Francisco, CA: Jossey-Bass.

Newmann, F., Bryk, A., \& Nagaoka, J. (2001). Authentic intellectual work and standardized tests: Conflict or coexistence? Chicago, IL: Consortium on Chicago School Research.

Rosenthal, R., \& Jacobson, L. (1968). Pygmalion in the classroom: Teacher expectation and pupils' intellectual development. New York: Holt Rinehart and Winston.

Rowe, K. (2004, August). The importance of teaching: Ensuring better schooling by building teacher capacities that maximize the quality of teaching and learning provision implications of findings from the international and Australian evidence-based research. Paper presented the summit conference on the Performance, Management and Funding of Australian Schools, University of Melbourne, Australia.

Schlechty, P. (2002). Working on the work: An action plan for teachers, principals, and superintendents. San Francisco, CA: JosseyBass.

Sefa Dei, G. (2003). Schooling and the dilemma of youth disengagement. McGill Journal of Education, 38(2), 241-256.

Shor, I. (1987). Critical teaching and everyday life. Chicago: University of Chicago Press.

Shor, I. (1992). Empowering education: Critical teaching for social change. Chicago: University of Chicago Press. 
Shor, I. (1996). When students have power: Negotiating authority in a critical pedagogy. Chicago: University of Chicago Press.

Simon, R. I. (1992). Teaching against the grain : texts for a pedagogy of possibility. New York: Bergin \& Garvey.

Sing, M., \& Luke, A. (1996). Introduction. In B. Bernstein (Ed.), Pedagogy, symbolic control, and identity: Theory, research, critique. Washington, DC:Taylor \& Francis, London.

Smith, W., Butler-Kisber, L., LaRoque, L., Portelli, J., Shields, C., Sturge Sparkes, C., \& Vibert, A. (1998). Student engagement in learning and school life: National project report. Montreal, QC: McGill University, Office of Research in Educational Policy Montreal,

Vibert A., \& Shields, C. (2003). Approaches to student engagement: Does ideology matter? McGill Journal of Education, 38(2), 221-239.

Vibert, A. B., Portelli J, Shields, C., \& LaRoque, L. (2002). Critical Practice in Elementary Schools: Voice, Community, and a Curriculum of Life. Journal of Educational Change, 3(2), 93-116.
Zyngier, D. (2003) Connectedness-isn't it time that education came out from behind the classroom door and rediscovered Social Justice, Social Alternatives, 22(3), 41-49. http://www.viterbo.edu/campnews/camp pub/analytic/

Zyngier, D. (2004b). Doing education not time. Engaging Pedagogies and Pedagogueswhat does student engagement look like in action? Paper presented at the AARE Annual Conference: Doing the Public Good, Melbourne http://www.aare.edu.au/ 04pap/zyn04008.pdf

Zyngier, D. and Gale, T. (2003) Engaging programs: How are Australian schools responding to low student retention?, AARE Annual Conference: Education Risks, Research \& Dilemmas, AARE, Auckland New Zealand, December 2003

Zyngier, D. (2007) Listening to TeachersListening to Students Substantive conversations about resistance, empowerment and engagement. Teachers and Teaching Theory and Practice Journal. 13(4) 327347.

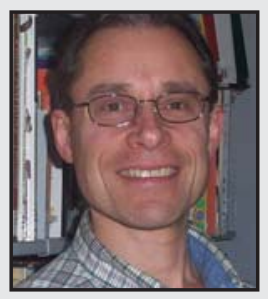

David Zyngier is a former Australian school principal and classroom teacher. After completing the development of the ruMAD Project for the Education Foundation, he commenced lecturing in the Faculty of Education at Monash University. The focus of his research is how school connectedness can improve student engagement and student outcomes, particularly for at risk students. He is leading researcher and developer of the program "Keymakers: Advancing Student Engagement through Changed Teaching Practice."

\section{LINKS:}

http://education.qld.gov.au/public_media/reports/curriculum-framework/qsrls/ http://www.education.monash.edu.au/profiles/dzyngier 